\title{
An innovative plant integrating PVT and geothermal reversible heat pump for heating and cooling in residential applications
}

\author{
Marco Pellegrini ${ }^{1}$, Giovanni Chiappa ${ }^{2}$ and Matteo Chiappa ${ }^{2}$ \\ 1 Department of Industrial Engineering, University of Bologna, Forlì (Italy) \\ 2 HDEMIA Srl, Merate (Italy)
}

\begin{abstract}
Many new technologies and projects are currently being undertaken worldwide to assist in the reduction of fossil fuel consumption. Significant progress has been made so far, and one promising solution moving towards a lowcarbon heating and cooling energy production in buildings is in the combined generation of renewable electricity and heat based on photovoltaic thermal collectors (PVT). In several European countries the PVT market is picking up speed. The possible applications for PVT-collectors are very varied and range from e.g. swimming pool heating to solar heat for industrial processes, but many of the already installed PVT systems have been applied to cover thermal and electrical energy demand at residential scale. The paper aims to show the results achieved in the power, heating and cooling production by a PVT plant integrated with geothermal reversible heat pump. The paper includes a description of the technology, the performance measured in a first installation and a preliminary economic assessment
\end{abstract}

Keywords: PVT, geothermal heat pump, solar heating and cooling, energy efficiency.

\section{Introduction}

Cities are fundamental in the world's transition to a low-carbon economy, since cities account for about $65 \%$ of global energy use and about $70 \%$ of man-made carbon emissions. While many cities have so far focused primarily on energy efficiency, the next step towards an urban sustainable energy system will require a significant increase in the use of renewable energy. Renewables can bring tremendous benefits to cities, including cleaner air, modern services and improved living spaces, and have huge impacts on several sectors, from buildings to transport, from lighting to industry.

Photovoltaic (PV) modules and solar thermal collectors are being installed in residential buildings and in some industrial utilities to respectively produce electrical and thermal energy. Both technologies have been widely applied and demonstrated to be reliable and effective (Weiss and Spork-Dur, 2020). Photovoltaic thermal (PVT) collectors can be considered as an hybrid technology combining PV and solar thermal components into a single module to simultaneously generate electricity and heat. The integration of PV and solar thermal technology in one device enhances solar energy conversion efficiency and also achieves optimized use of surfaces. Different kinds of PVT collectors have been tested in different locations, therefore a wide literature exists (Joshi and Dhoble, 2018).

PVT market is a niche market if compared with solar thermal and PV; nevertheless, by the end of 2018 more than 1 million $\mathrm{m}^{2}$ of PVT collectors were installed in over 25 countries (Weiss and Spork-Dur, 2020): in the European market, France is the leader with an installed collector area of $484,587 \mathrm{~m}^{2}$ followed by Germany with $112,326 \mathrm{~m}^{2}$ and the Netherlands with $32,127 \mathrm{~m}^{2}$. In Italy, Spain and Switzerland, collector areas range between $10,000 \mathrm{~m}^{2}$ and $15,000 \mathrm{~m}^{2}$. Indeed, the Italian market already showed a great interest in PVT collectors since 2010-2012, when a local increasing of both PVT collectors manufacturers and sales were observed as well as a growing interest from the research field (Aste et al., 2014; Bianchini et al., 2017). Nevertheless, at the time PVT collectors were not cost competitive with PV modules and/or solar thermal collectors and not reliable enough. Now, the market is demonstrating a growing interest in the technology, especially in combination with other renewables. In fact, the non-availability and unpredictability of solar source all the time throughout the year has led to research in the area 
of solar hybrid renewable energy systems (HRESs). In the past few years, a lot of research has taken place in the design, optimization, operation and control of HRESs (Rekioua,2020). In particular, the integration of PVT with several geothermal systems have been explored, like PVT and heat pumps with borehole heat exchangers (Bertram et al., 2011; Yao et al., 2020) or PVT and open-loop ground source heat pumps (Pellegrini et al., 2019; Hoekstra et al., 2020). Since PVT collectors can be substantially classified into systems that are designed to optimize the heat production or the power production, several combinations of PVT, heat pumps and geothermal for renewable power, heating and cooling generation in buildings can be found in literature.

The paper aims to introduce a novel hybrid renewable energy system, called "Geosolzero", able to cover power, space heating and cooling and domestic hot water (DHW) demand of a single-family house. This system consists of two arrays of PV modules and PVT collectors integrated with a geothermal reversible heat pump. The novelty of the system is related to i) the optimization of power production of PVT collectors and ii) the patented design of the ground plate heat exchangers. The paper includes a description of the plant, the performance measured in a first single-family house installation in Northern Italy and a preliminary economic assessment. Geosolzero plant has been included in the list of representative PVT worldwide plants mapped by the IEA SHC Task 60 "Application of PVT collectors" (Ramschack et al., 2020).

\section{Description of the plant}

The Geosolzero system has been firstly installed in 2016 in a renovated single-family house in Suello (Italy). The town of Suello is located in the North of Italy, close to the lake of Annone, which is $50 \mathrm{~km}$ from Milan. Suello is about 300 meters above sea level and it is characterized by 2,460 heating degrees days and a mean annual solar radiation of about $1,400 \mathrm{kWh} / \mathrm{m}^{2}$. The building is certified as Class $\mathrm{A}+$ and has an area of about $250 \mathrm{~m}^{2}$ that is thermally controlled by a HVAC system (in Figure 1 an extract of the executive project of the building).

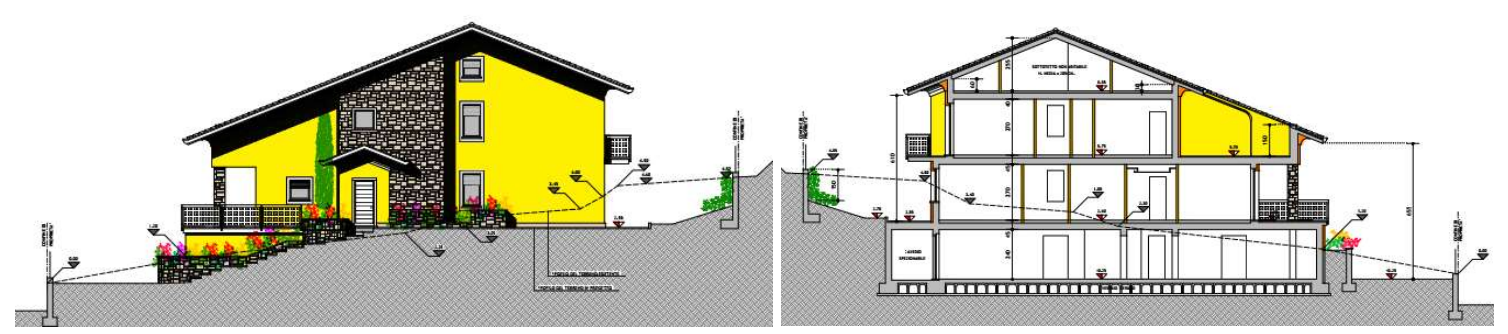

Fig. 1: The executive project of the single-family house in Suello.

The Geosolzero system includes a reversible heat pump, two storage tanks (one for hot/cold water and one for DHW, both with a capacity of $0.3 \mathrm{~m}^{3}$ ), 16 unglazed PVT collectors, 16 PV modules and two patented ground plate heat exchangers PVT collectors coolant fluid is a mixture of water and glycol (30\%). PV modules and PVT collectors are installed on the house roof. More in detail, the PVT collectors are Solink HBK250850 with a total collector area of $26.08 \mathrm{~m}^{2}$ and $4 \mathrm{~kW}$ peak electrical output. PVT collectors are oriented to the South with an inclination angle of $35^{\circ}$. The PV modules are installed with the same orientation and comprises modules of the same PVT type, i.e. though without heat absorbers $\left(26.08 \mathrm{~m}^{2}\right.$ and $4 \mathrm{~kW}$ peak). Information about PVT collectors (both electric and thermal) and PV modules (only electric) are summarized in Table 1. The electric power produced by both PVT collectors and PV modules is converted into alternating current via one ABB Trio inverter (model 8.5) with two MPPT strings.

Tab. 1: Main electric and thermal characteristics of the PVT collectors (Solink HBK250850). Thermal characteristics are referred to the aperture area.

\begin{tabular}{|c|c|}
\hline \multicolumn{2}{|c|}{ Electric characteristics } \\
\hline Electric power at STC conditions & $250 \mathrm{~W}( \pm 3 \%)$ \\
\hline Aperture area & $1.570 \mathrm{~m} \times 0.920 \mathrm{~m}$ \\
\hline NOCT & $44^{\circ} \mathrm{C}$ \\
\hline
\end{tabular}




\begin{tabular}{|c|c|}
\hline MPP voltage & $29.2 \mathrm{~V}$ \\
\hline MPP current & $8.45 \mathrm{~A}$ \\
\hline Open circuit voltage & $37.6 \mathrm{~V}$ \\
\hline Short circuit current & $8.91 \mathrm{~A}$ \\
\hline Power loss thermal coefficient & $-0.44 \% /{ }^{\circ} \mathrm{C}$ \\
\hline Thermal characteristics & \\
\hline Max stagnation temperature & $83^{\circ} \mathrm{C}$ \\
\hline Nominal thermal power & $849 \mathrm{~W}( \pm 1.6 \%)$ \\
\hline Peak thermal efficiency & $49.1 \%$ \\
\hline Linear coefficient of thermal dispersion a1 & $10.04 \mathrm{~W} / \mathrm{m}^{2} \mathrm{~K}$ \\
\hline Quadratic coefficient of thermal dispersion a2 & $0.000 \mathrm{~W} / \mathrm{m}^{2} \mathrm{~K}^{2}$ \\
\hline Time constant C & $147 \mathrm{~s}$ \\
\hline Thermal capacity K & $31.4 \mathrm{~kJ} / \mathrm{K}$ \\
\hline Max coolant flowrate per module & $0.12 \mathrm{~m} / \mathrm{h}$ \\
\hline
\end{tabular}

In the summer (Figure 2 the building is cooled through the reversible heat pump, which is electrically driven by the PVT collectors and PV modules, while the condenser is connected to one ground plate heat exchanger. PVT collectors are cooled by another twin ground plate heat exchange. Heat pump and PVT collectors circuits are disconnected since manual valves on the lines are closed.

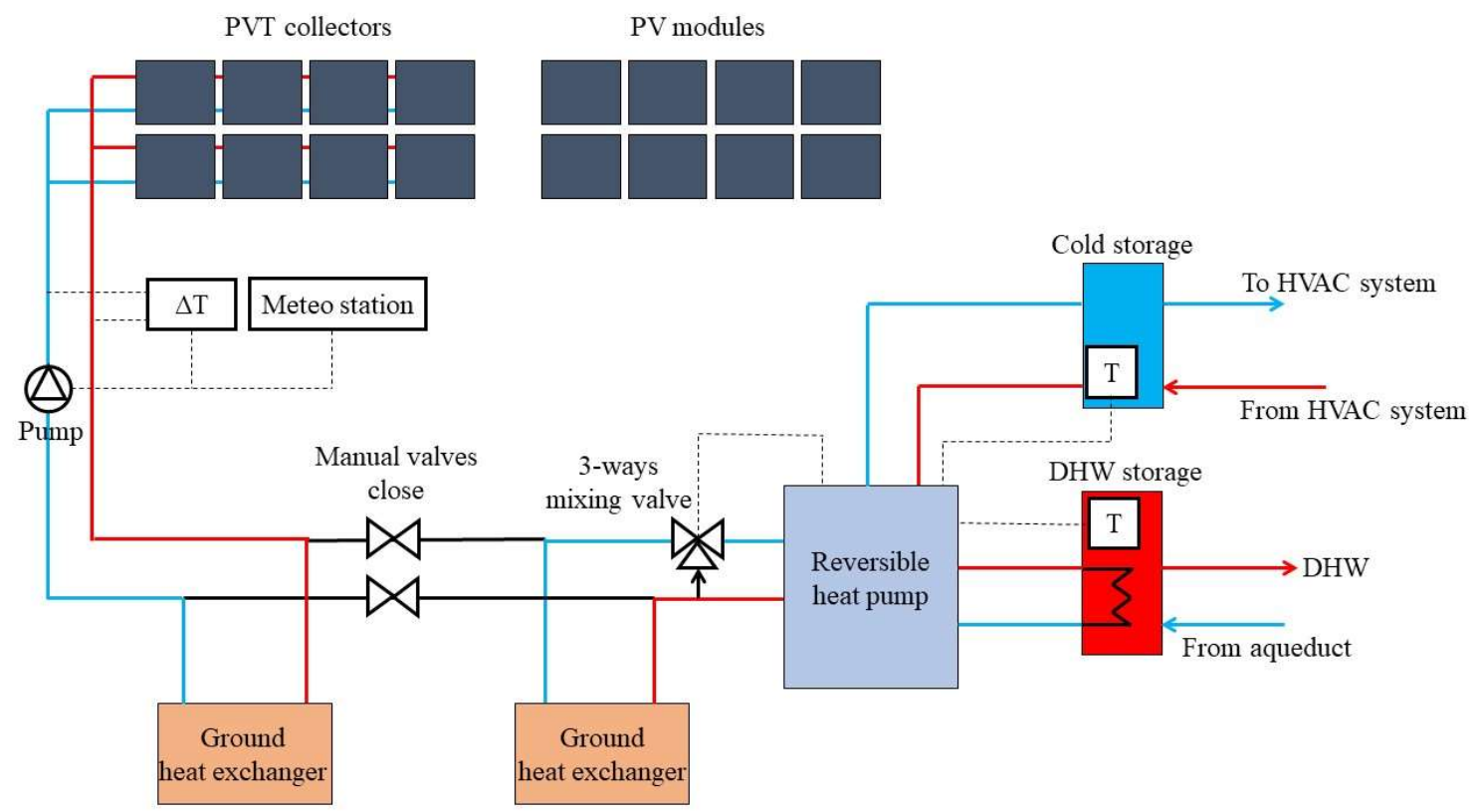

Fig. 2: P\&ID of the system and hot/cold flowrate in summertime operation.

In the winter (Figure 3), the manual valves are open and the heat produced by PVT collectors is used on the evaporator side of the heat pump, together with the heat extracted by the ground. In both seasons the production of DHW is directly managed by the reversible heat pump control unit: when DHW is required by the user, an internal 3-ways valve gives priority to the production of DHW in both summer or winter time. The heating and 
cooling supply system is depicted accordingly to (Jonas, 2019) in the simplified form in Figure 4.

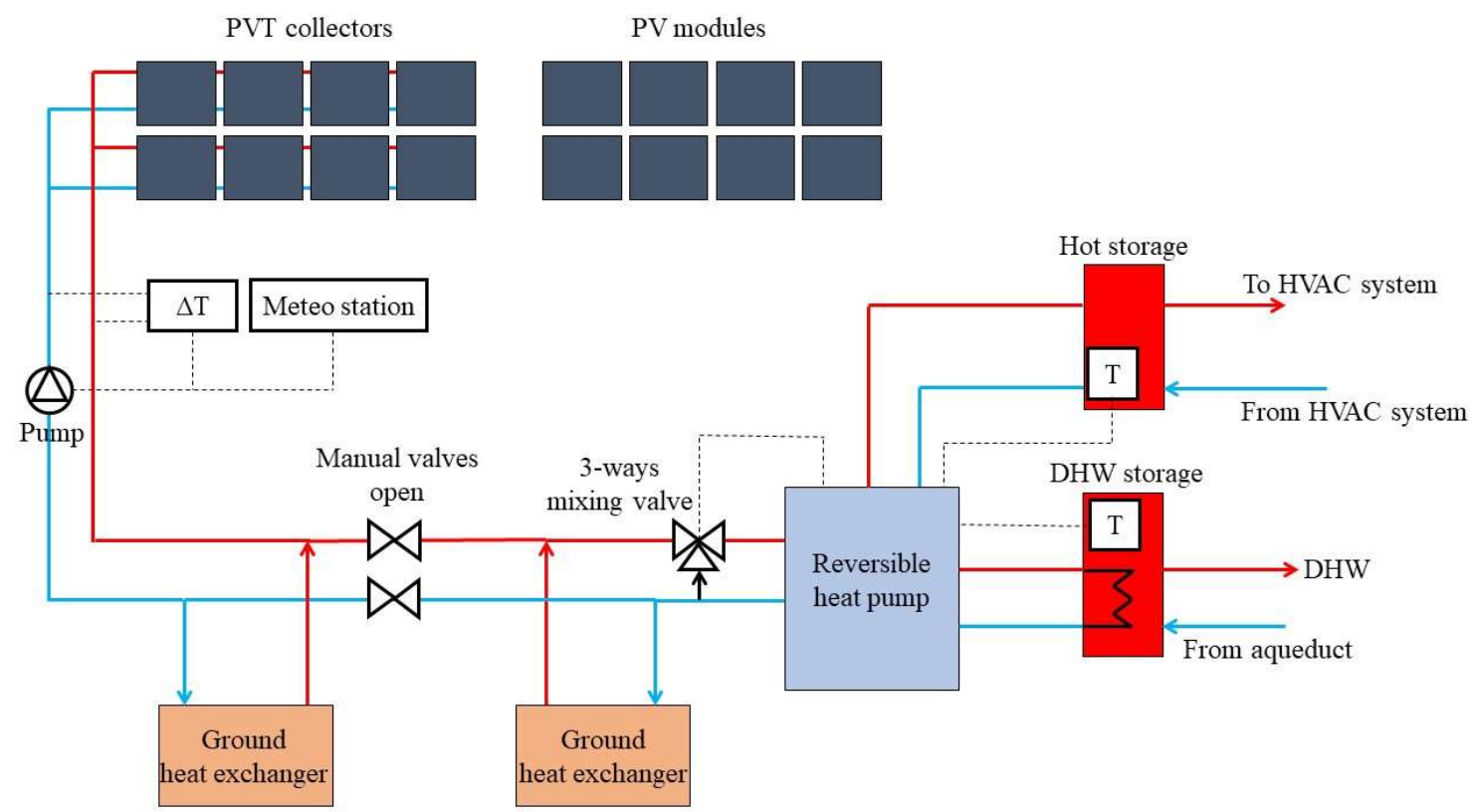

Fig. 3: P\&ID of the system and hot/cold flowrate in wintertime operation,

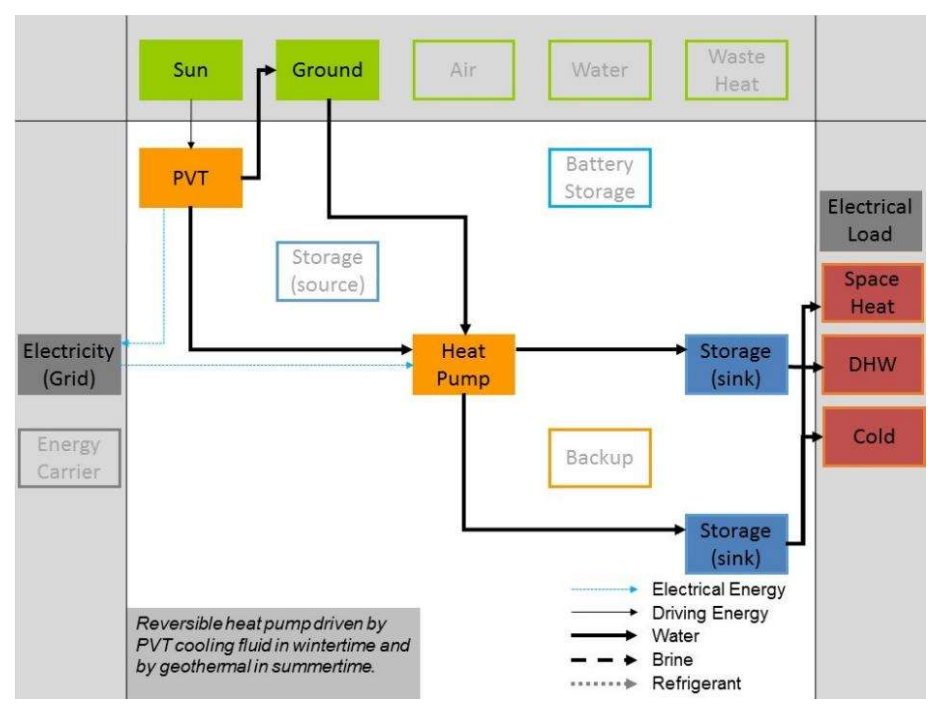

Fig. 4: Visualization of the integrated PVT plant.

The characteristics of the reversible heat pump are summarized in Table 2, while the information about the ground plate heat exchangers are in Table 3. In particular, the ground plate heat exchangers have been designed by HDEMIA for the integration in the plant concept as a further renewable source/sink able to integrate or compensate the energy contribution coming from the PVT collectors.

Tab. 2: Main electric and thermal characteristics of the reversible heat pump installed in the plant.

\begin{tabular}{|c|c|}
\hline \multicolumn{2}{|c|}{ Main characteristics } \\
\hline Manufacturer & ENEREN \\
\hline Model & ENX012HL \\
\hline Refrigerant & R410A \\
\hline
\end{tabular}




\begin{tabular}{|c|c|}
\hline Size & $0.803 \mathrm{~m} \times 0.606 \mathrm{~m} \times 1.247 \mathrm{~m}$ \\
\hline \multicolumn{2}{|c|}{ Cooling operation (chiller) @ condenser $30 \div 35^{\circ} \mathrm{C}$} \\
\hline Cooled fluid temperature@evaporator & $7 \div 12^{\circ} \mathrm{C}$ \\
\hline Cooling power & $2.50 \div 10.10$ \\
\hline Power consumption (including internal pumps) & $0.50 \div 2.60$ \\
\hline EER & $5.19 \div 3.91$ \\
\hline \multicolumn{2}{|c|}{ Heating operation (heat pump) @ evaporator $0 \div-3^{\circ} \mathrm{C}$} \\
\hline Heated fluid temperature@condenser & $30 \div 35^{\circ} \mathrm{C}$ \\
\hline Heating power & $2.30 \div 9.90$ \\
\hline Power consumption (including internal pumps) & $0.40 \div 2.30$ \\
\hline $\mathrm{COP}$ & $5.25 \div 4.32$ \\
\hline \multicolumn{2}{|c|}{ Heating operation (heat pump) @ evaporator $10 \div 5^{\circ} \mathrm{C}$} \\
\hline Heated fluid temperature @condenser & $30 \div 35^{\circ} \mathrm{C}$ \\
\hline Heating power & $3.00 \div 12.80$ \\
\hline Power consumption (including internal pumps) & $0.40 \div 2.40$ \\
\hline $\mathrm{COP}$ & $7.04 \div 5.22$ \\
\hline \multicolumn{2}{|c|}{ DHW production@evaporator $10 \div 5^{\circ} \mathrm{C}$} \\
\hline DHW@condenser & $50 \div 55^{\circ} \mathrm{C}$ \\
\hline Heating power & $2.70 \div 11.50$ \\
\hline Power consumption (including internal pumps) & $0.70 \div 3.40$ \\
\hline $\mathrm{COP}$ & $3.74 \div 3.35$ \\
\hline
\end{tabular}

Tab. 3: Main characteristics of the ground heat exchangers.

\begin{tabular}{|c|c|}
\hline Plate size & $1.500 \mathrm{~m} \times 0.750 \mathrm{~m}$ \\
\hline Plate weight & $6.5 \mathrm{~kg}$ \\
\hline Number of plates & 6 per heat exchanger \\
\hline Installation depth & Under $5 \mathrm{~m}$ \\
\hline Max fluid flowrate per plate & $0.3 \mathrm{~m}^{3} / \mathrm{h}$ \\
\hline Plate material & Anodised aluminium with protective coating in PVC \\
\hline
\end{tabular}

The coolant flowrate through the PVT collectors is guaranteed by a pump (Grundfos SOLAR PML 25-145) and it is controlled by a solar thermal differential temperature unit (PAW SC3.6). Therefore, the control strategy of the PVT cooling system is based on keeping constant the temperature difference between PVT arrays inlet and outlet through the control of the coolant flowrate. The operation of the reversible heat pump is controlled by its own control unit: in particular, the reversible heat pump control unit manages i) the 3-way mixing valve that optimizes the inlet temperature from the heat source/sink and ii) all the inverters installed on refrigerant 
compressor and fluid pumps motors to optimize the differential temperatures in the heat exchangers through flow rate control on the evaporator and condenser sides. As mentioned before, the reversible heat pump control unit also manages the DHW production. A Siemens RLU220 controller has been installed for the monitoring and control of the whole plant, including temperature monitoring (via Siemens QAD22 temperature sensors) in the hot/cold water and DHW storages. The control logic has not been implemented yet due to the difficulties in integrating the control units of the PVT coolant circulating pump and of the reversible heat pump (SHC IEA, 2014).

The advantage in the adoption of the described ground configuration is that the geothermal closed-loop is realized with a compact and easy to install device (i.e. the ground plate heat exchanger) that can be applied with relatively low cost also in existing buildings. In fact, in comparison with the proposed solution, the realization of close-loop systems usually requires larger area for horizontal borehole heat exchangers or greater depth for vertical borehole heat exchangers (Rees, 2016). Another option is the integration of PVT collectors with open-loop geothermal systems, i.e. the direct use of groundwater as heat source or sink, but with higher investment and maintenance and operation costs (Rees, 2016). Nevertheless, the application of HDEMIA ground heat exchangers can concentrate the heat exchange in a relatively small volume, and so the risk of local thermal short circuit may be expected.

\section{Techno-economic assessment}

Based on the building executive project, the users yearly energy demand was calculated in $26.89 \mathrm{kWh} / \mathrm{m}^{2}$ for space heating, $5.36 \mathrm{kWh} / \mathrm{m}^{2}$ for space cooling and $467 \mathrm{kWh}$ el for DHW production. Over the years the system has been monitored to evaluate its performances and the real behavior of the users.

The mean yearly energy demand for space heating results as about $11,750 \mathrm{kWh}$ (i.e. $47.00 \mathrm{kWh} / \mathrm{m}^{2}$ per year, that is $75 \%$ more than expected). The difference between calculated and measured energy consumption for space heating is due by the users behavior, since the rooms' set points for space heating were found to be set at temperature much higher than the standard $20^{\circ} \mathrm{C}$ in wintertime. The whole energy demand is covered by the heat pump, since the plant has no thermal auxiliaries (i.e. natural gas or electric boilers). Therefore, the design of the plant results in a good capacity to cover also heating peak requests higher than expected. The mean yearly energy demand for space cooling results as about $1,408 \mathrm{kWh}$ (i.e. $5.63 \mathrm{kWh} / \mathrm{m}^{2}$ per year, that is $5 \%$ more than calculated). In that case, the user needs are in good agreement with the expected energy consumption. The energy demand for DHW production has been estimated on the basis of heat pump operation while no space heating or cooling demand was present. The mean yearly consumption of DHW has been estimated in $512 \mathrm{kWh}$ el per year, once again in good agreement with the design forecasts.

The seasonal COP of the heat pump in winter (including DHW production) has been assessed in 4.04, while the EER of the reversible heat pump in summer (including DHW production) has been assessed in 3.93. COP and EER have been both computed by considering as system boundary the reversible heat pump. Further investigations, including a revamping of the monitoring system, would be necessary to evaluate the plant performances at extended boundaries.

The PVT plant has a mean yearly energy production of about 5,200 kWh el (DC side) plus $16,320 \mathrm{kWh}$ th. While the electric energy produced is used to power the heat pump all over the year, only a small amount of the heat produced by the PVT plant is directly used for the users, i.e. less than $10 \%(1,438 \mathrm{kWh}$ th), via the heat pump. Nevertheless, the amount of heat sunk in the ground in the summertime has beneficial effects on the heat pump operation at the beginning of the winter season, but this contribution is not easy to assess without a proper monitoring system. The rest of the heat (over 90\%) produced by the PVT collectors is sunk in the ground. Therefore, the logic of the plant is to optimize PVT power production through collectors cooling at relatively low temperatures, while penalizing the heat recovery. The final result is that the PVT plant power production over the year is able to cover space heating and cooling and DHW demands. In fact, while the power demands for space heating, space cooling and DHW production are, respectively, 2,908 kWh, $358 \mathrm{kWh}$ and $512 \mathrm{kWh}$, with a total amount of 3,778 kWh per year, the PVT plant alone is able to produce about 4,992 kWh (including inverter efficiency). Hence, the electricity produced every year by the PVT plant exceeds the reversible heat pump consumption. Nevertheless, since the power consumption and power production is not contemporary, and there is no electric storage in the building, based on the monthly energy bills the electricity self-sufficiency fraction of the system can be estimated in $25 \%$. 
Due to the characteristic of the plant installed in Suello, it is possible to compare the seasonal electric performances of the PVT collectors and the same PV modules, i.e. PVT collectors with and without active cooling. It is interesting to note how PVT collectors are able to produce up to $10 \%$ more than the PV plant, thus maximizing solar power production when needed. Another interesting finding resulted from the plant operation is the implementation of a control strategy which has been implemented as "ground night cooling", i.e. the use of PVT collectors during the night to cool down the ground when consecutive summer days with high air temperature peaks are registered. This strategy, which is beneficial for the reversible heat pump operation and EER, may need further investigation to evaluate how the night coolant circulation may affect the seasonal efficiency of the whole system.

The investment cost of the whole system is about 39,000 $€$ (VAT excluded), while yearly operation and maintenance costs can be estimated in not more than $1 \%$ of the initial investment. The so-called "levelised cost of energy" (LCOEn) generated by the system can be expressed as in Equation 1:

$$
L C O E n=\frac{I_{0}+\sum_{t=1}^{T=25}\left(O M_{t}-E_{P V T}^{E l} \cdot P_{e l}\right) \cdot(1+r)^{-t}}{\sum_{t=1}^{T=25}\left(Q_{s y s}+C_{s y s}+Q_{D H W}\right) \cdot(1+r)^{-t}}
$$

where: $\mathrm{I}_{0}$ is the initial investment (not including the PV modules); $\mathrm{OM}_{\mathrm{t}}$ are operation and maintenance costs in the year; $\mathrm{E}^{\mathrm{El}}{ }_{\mathrm{PVT}}$ is the electric energy produced by the PVT and sold to the grid; $\mathrm{P}_{\mathrm{el}}$ is the price at which the electric energy produced by the PVT is sold; $\mathrm{Q}_{\text {sys }}$ and $\mathrm{C}_{\text {sys }}$ are, respectively, the heat and cold delivered to the end-users; $\mathrm{Q}_{\mathrm{DHW}}$ is the DHW production; $\mathrm{t}$ is the year, with a whole period of analysis of 20 years; $r$ is the discount rate. Table 4 summarizes the main parameters considered in the economic assessment. It should be noted that i) the selling price considers the "net metering" option that is available in Italy for PV or PVT installations under 20 $\mathrm{kW} \mathrm{p}$ and ii) the initial investment do not take into account the $50 \%$ tax credit that is available for such a kind of investment in Italy.

Tab. 4: Economic parameters considered in the economic assessment.

\begin{tabular}{|c|c|c|}
\hline Parameter & Symbol & Value \\
\hline Initial investment & $\mathrm{I}_{0}$ & $39,000 €$ \\
\hline Period analysis & $\mathrm{T}$ & 20 years \\
\hline Yearly operation and maintenance cost & $\mathrm{OM}_{\mathrm{t}}$ & $390 € /$ year \\
\hline Yearly electric energy sold to the grid & $\mathrm{E}^{\mathrm{El}} \mathrm{PVT}_{\mathrm{f}}$ & $1,700 \mathrm{kWh} /$ year \\
\hline Electric energy selling price & $\mathrm{P}_{\mathrm{el}}$ & $0.09 € / \mathrm{kWh}$ \\
\hline Yearly heat delivered to the user & $\mathrm{Q}_{\mathrm{sys}}$ & $11,750 \mathrm{kWh} /$ year \\
\hline Yearly cooling energy delivered to the user & $\mathrm{C}_{\mathrm{sys}}$ & $1,408 \mathrm{kWh} /$ year \\
\hline Yearly DHW delivered to the user & $\mathrm{Q}_{\mathrm{DHW}}$ & $2,040 \mathrm{kWh} /$ year \\
\hline Discount rate & $\mathrm{r}$ & $4 \%$ \\
\hline
\end{tabular}

The LCOEn of the system described in the paper is $0.20 € / \mathrm{kWh}$ : the LCOEn is reduced to $0.11 € / \mathrm{kWh}$ if the tax credit is considered. Since heat, cold and electricity are generally not considered to have the same value per unit of energy, it would be useful to define the levelised costs of the different energy forms separately. Nevertheless, the allocation (splitting) of the total costs to the different energy contributions is to some extent a matter of convention. Therefore, the authors preferred to compute the whole LCOEn to be compared with other heating/cooling options in the same boundary conditions or application. 


\section{Conclusions}

The paper shows the results of 3 years of operation of an innovative plant for building heating and cooling. The plant includes 16 PVT collectors, a reversible heat pump, two storage tanks and two ground heat exchangers. The plant control strategy is dedicated to the optimization of the PV operation to maximize the power output of the plant. The plant demonstrated to be effective in satisfying the energy demand coming from the users. Further optimizations are possible to increase the seasonal COP/EER through a more sophisticated control system which should integrate together the solar circulating pump and the heat pump control units.

\section{References}

Aste, N., del Pero, C., Leonforte, F., 2014. Water flat plate PV-thermal collectors: A review. Sol. Energ. 102, 98115. https://doi.org/10.1016/j.solener.2014.01.025

Bertram, E., Stegmann, M., Rockendorf, G., 2011. Heat Pump Systems with Borehole Heat Exchanger and Unglazed PVT-Collector. Proceedings of the Solar World Conference 2011. https://doi:10.18086/swc.2011.26.02

Bianchini, A., Guzzini, A., Pellegrini, M., Saccani, C., 2017. Photovoltaic/thermal (PV/T) solar system: experimental measurements, performance analysis and economic assessment. Renew. Energ. 111, 543-555. https://doi.org/10.1016/j.renene.2017.04.051

Hoekstra, N., Pellegrini, M., Bloemendal, M., Spaak, G., Andreu Gallego, A., Rodriguez Comins, J., Grotenhuis, T., Picone, S., Murrell, A.J., Steeman, H.J., Verrone, A., Doornenbal, P., Christophersen, M., Bennedsen, L., Henssen, M., Moinier, S., Saccani, C., 2020. Increasing market opportunities for renewable energy technologies with innovations in aquifer thermal energy storage. Sci. Total Environ. 709, 136142. https://doi.org/10.1016/j.scitotenv.2019.136142

Jonas, D., 2019. Visualization of energy flows in PVT systems. https://doi.org/10.18777/ieashc-task60-2019-0001 Joshi , S.S., Dhoble, A.S., 2018. Photovoltaic-Thermal systems (PVT): Technology review and future trends. Renew. Sust. Energ. Rev. 92, 848-882. https://doi.org/10.1016/j.rser.2018.04.067

Pellegrini, M., Hoekstra, N., Bloemendal, M., Andreu Gallego, A., Rodriguez Comins, J., Grotenhuis, T., Mazzoni, M., Picone, S., Murrell, A.J., Steeman, H.J., Spaak, G., 2019. Low carbon heating and cooling by combining various technologies with Aquifer Thermal Energy Storage. Sci. Total Environ. 665, 1-10. https://doi.org/10.1016/j.scitotenv.2019.01.135

Ramschak, T., Baggenstos, A., Mellor, A., Gagliano, A., Corino, C., Zenhäusern, D., Cabral, D., Ryan, G., Guedea, I., Brottier, L., Ruoff, U., Schubert, M., Lämmle, M., Pellegrini, M., Dannemand, M., Cañada, M., Radisch, N., Pokorny, N., 2020. Existing PVT Systems and Solutions. https://doi.org/10.18777/ieashc-task60$\underline{2020-0001}$

Rees, S.J., 2016. Advances in Ground-Source Heat Pump Systems, first ed. Woodhead Publishing, Sawston. https://doi.org/10.1016/C2014-0-03840-3

Rekioua, D., 2020. Hybrid Renewable Energy Systems Overview. In: Hybrid Renewable Energy Systems. Green Energy and Technology. Springer, Cham. https://doi.org/10.1007

SHC IEA, 2014. Solar and Heat Pump Systems, Position Paper, Task 44/Annex 38 Solar and Heat Pump Systems.

Weiss, W., Spork-Dur, M., 2020. Solar Heat Worldwide.

Yao, J., Liu, W., Zhang, L., Tian, B., Dai, Y., Huang, M., 2020. Performance analysis of a residential heating system using borehole heat exchanger coupled with solar assisted PV/T heat pump. Renew. Energ. 160, 160-175. https://doi.org/10.1016/j.renene.2020.06.101 